\title{
Distribution and abundance of the alien Xylosandrus germanus and other ambrosia beetles (Coleoptera: Curculionidae, Scolytinae) in different forest stands in central Slovenia
}

\author{
Tine Hauptman, \\ Roman Pavlin, \\ Petra Grošelj, \\ Maja Jurc
}

\begin{abstract}
The East Asian ambrosia beetle (Xylosandrus germanus - Blandford 1894) is an invasive species that has become successfully established in Europe and North America. In Slovenia, $X$. germanus was first recorded in 2000 in the western part of the country, and since 2008 the species has also been identified in other parts of Slovenia. The first economic damage was recorded in 2016 after a massive attack on recently felled logs of different tree species, spurring research into this non-native invasive species. To examine the distribution and abundance of $X$. germanus compared to other ambrosia beetles and to determine voltinism and the flight period of the species in our climatic conditions, we deployed 19 ethanol-baited traps from March to November 2017 in oak-, beech- and fir-dominated forest stands in central Slovenia. To verify the vertical distribution of $X$. germanus, traps were installed at altitudes ranging from $303 \mathrm{~m}$ to $941 \mathrm{~m}$ a.s.l. Furthermore, the impact of the ice storm that hit Slove nia in 2014 on the abundance of $X$. germanus was also studied. Non-native $X$. germanus represented $71.8 \%$ of the total catch and was significantly more abundant than the other five most common species: Xyleborinus saxesenii (20.0\%), Xyleborus monographus (3.6\%), Anisandrus dispar (2.5\%), Trypodendron domesticum (1.2\%) and Trypodendron signatum $(0.6 \%)$. X. germanus was most abundant in beech-dominated stands, but the differences between forest types were not significant. The species was found along the entire altitudinal gradient. Our results indicate that the swarming of $X$. germanus in lowland forests may already occur by the middle of March. Maximum flying activity was observed in May and early June in forests below $600 \mathrm{~m}$ a.s.l. and at the end of May and in June in forests above $700 \mathrm{~m}$ a.s.l. Only one generation per year was observed. The ice storm positively affected the abundance of $X$. germanus, especially in areas where sanitary logging was delayed. Xyleborinus attenuatus was detected for the first time in Slovenia.
\end{abstract}

Keywords: Xylosandrus germanus, Ambrosia Beetles, Black Timber Bark Beetle, Invasive Species, Habitat Preference, Monitoring, Ethanol-baited Traps

\section{Introduction}

Ambrosia beetles are weevils from the Scolytinae and Platypodinae subfamilies (Coleoptera: Curculionidae) that are obligately associated with nutritional fungal symbionts (Hulcr et al. 2015). They usually excavate tunnels in the wood of dead or stressed trees in which they actively cultivate ambrosia fungi. Because of their hid- den way of life (most of the time they reside within the wood), they can be easily and imperceptibly transported to new environments (Rassati et al. 2016a). Many species are polyphagous and have haplodiploid reproduction and sibling mating behavior. All these features allow small founder populations to rapidly establish and spread in new environments (Kirken- $\square$ Department of Forestry and Renewable Forest Resources, Biotechnical Faculty, University of Ljubljana, Večna pot 83, SI-1000 Ljubljana (Slovenia)

@ Tine Hauptman (tine.hauptman@bf.uni-lj.si)

Received: Mar 29, 2019 - Accepted: Jul 27, 2019

Citation: Hauptman T, Pavlin R, Grošelj P, Jurc M (2019). Distribution and abundance of the alien Xylosandrus germanus and other ambrosia beetles (Coleoptera: Curculionidae, Scolytinae) in different forest stands in central Slovenia. iForest 12: 451-458. - doi: 10.3832/ifor3114-012 [online 2019-09-29]

Communicated by: Massimo Faccoli dall 1983). Therefore, ambrosia beetles are one of the most successful groups of invasive species worldwide (Kirkendall \& Faccoli 2010).

The black timber bark beetle Xylosandrus germanus (Blandford, 1894) is native to East Asia (Kirkendall \& Faccoli 2010). In Europe, it was first recorded in 1952 in Germany (Groschke 1953). In the last two decades of the $20^{\text {th }}$ century, the species was also recorded in Austria, Belgium, France, Italy, Poland and Switzerland. After the year $2000 \mathrm{X}$. germanus spread throughout Europe and is now present in Croatia, the Czech Republic, Denmark, Hungary, the Netherlands, Romania, the Russian Federation, Slovakia, Slovenia, Spain, Sweden, Turkey, the United Kingdom and Ukraine (Björklund \& Boberg 2017a, EPPO 2018, Galko et al. 2019).

In Slovenia, $X$. germanus was recorded for the first time in 2000. It was found on an infested sweet chestnut tree (Castanea sativa Mill.) in the western part of the country (Jurc et al. 2010, Seljak 2013). Since 
2008, the species has also been identified in other parts of Slovenia. It has often been caught in traps intended for monitoring Monochamus beetles (Coleoptera: Cerambycidae), and in a few cases, infestations of visually healthy trees have been found (Jurc et al. 2010, 2011, 2012).

The first economic damage was recorded in 2016, when $X$. germanus infested a large amount of timber that was not removed from the forest immediately after logging (Hauptman et al. 2018). In addition to finding $X$. germanus in sweet chestnut trees, we have also found infestations on Norway spruce (Picea abies [L.] H. Karst), silver fir (Abies alba Mill.), Scots pine (Pinus sylvestris L.), common beech (Fagus sylvatica L.) and sessile oak (Quercus petraea [Mattuschka] Liebl.).

In North America, where the species was introduced in 1932, X. germanus is one of the most economically important ambrosia beetle pests in nurseries (Ranger et al. 2016), while in Europe it is considered a secondary pest (Henin \& Versteirt 2004, Lakatos \& Kajimura 2007). However, in some parts of Europe, $X$. germanus has become one of the most common scolytid species (Grégoire et al. 2001, Henin \& Versteirt 2004, Bouget \& Noblecourt 2005, Holzinger et al. 2014, Rassati et al. 2016a) and is considered to have the potential to affect native scolytid communities (Henin \& Versteirt 2004).

$X$. germanus is extremely polyphagous (Weber \& McPherson 1983). However, in Italy, the forest type was recently found to have a significant effect on the activitydensity of the species (Rassati et al. 2016a). The abundance of $X$. germanus in ethanolbaited traps was significantly higher in chestnut-dominated (C. sativa) forests than in forests dominated by hop hornbeam (Ostrya carpinifolia Scop.) and beech (F. syl- vatica). Furthermore, temperature was also found to have a positive impact on the activity-density of $X$. germanus, meaning that low temperatures limit its spread to high-elevation forests (Rassati et al. 2016a). In Europe an elevation limit of $500 \mathrm{~m}$ a.s.l. was proposed by Bruge (1995), but a study from Romania (Olenici et al. 2014) states that $X$. germanus was found at an altitude of 760 to $900 \mathrm{~m}$ a.s.l. Similar findings have recently been reported from Slovakia (Galko et al. 2019). The number of generations per year also depends primarily on environmental temperatures. In Central Europe, $X$. germanus is considered to be monovoltine (Bruge 1995, Henin \& Versteirt 2004), but in Italy, two generations per year have been observed (Rassati et al. 2016b).

The main aim of this study was to examine the distribution and abundance of $X$. germanus and other ambrosia beetles in different forest stands dominated by different tree species and at different altitudes in the central part of Slovenia. Furthermore, we also wanted to determine voltinism and the flight period of $X$. germanus in our climatic conditions. Forests damaged due to natural disasters are an appropriate habitat for the development of the species (Jurc et al. 2010); therefore, the impact of the 2014 ice storm on the abundance of $X$. germanus was also studied.

\section{Materials and methods}

\section{Research area}

The study was conducted in 19 different forest stands located in the wider area of the capital city of Ljubljana (Fig. 1). The selected stands are dominated (i.e., more than $50 \%$ of trees belong to a given species) by common beech ( $F$. sylvatica, 7 stands), sessile oak (Q. petraea, 7 stands) and silver fir (A. alba, 5 stands). The stands are located at altitudes ranging from $303 \mathrm{~m}$ to $941 \mathrm{~m}$ a.s.l. and were therefore divided into three altitudinal groups: (I) lower altitudes, below 450 m a.s.l.; (II) medium altitudes, between 450 and $600 \mathrm{~m}$ a.s.l.; (III) higher altitudes, above $700 \mathrm{~m}$ a.s.l. (Tab. 1).

\section{Traps, lures and sampling}

In each stand, one black cross-vane panel trap (WitaPrall IntPt - Nassfalle, Witasek PflanzenSchutz $\mathrm{GmbH}$, Germany) was placed in the middle of a plot of at least 2 ha where a particular tree species dominates. However, these plots are a part of a larger forest area where a particular species is the most common tree species. Traps were hung on a tree branch approximately two meters above the ground and at least $50 \mathrm{~m}$ from the forest edge. All traps were equipped with a half-liter plastic bottle without a cap, containing $200 \mathrm{ml}$ of $96 \%$ ethanol as an attractant. The bottles were attached in the upper half of the traps. Furthermore, wet collecting cups filled with $200 \mathrm{ml}$ of antifreeze (80-98\% ethylene glycol - Arteco, Belgium) to preserve the collected entomofauna were positioned at the bottom of the traps. Traps were set in the period between 20 February 2017 and 7 March 2017. On 10 March 2017, traps were visited for the first time, and since then, traps were visited at 14-day intervals until 3 November 2017. Due to the different time settings of the traps, catch data from the period before 10 March 2017 were not included in the analysis.

On each visit, samples were collected from each trap. In total, 17 samples per trap were collected in the entire sampling period. After every sampling, the collecting cups were refilled with fresh ethylene glycol. On each visit, the amount of evaporated ethanol was also measured, and the

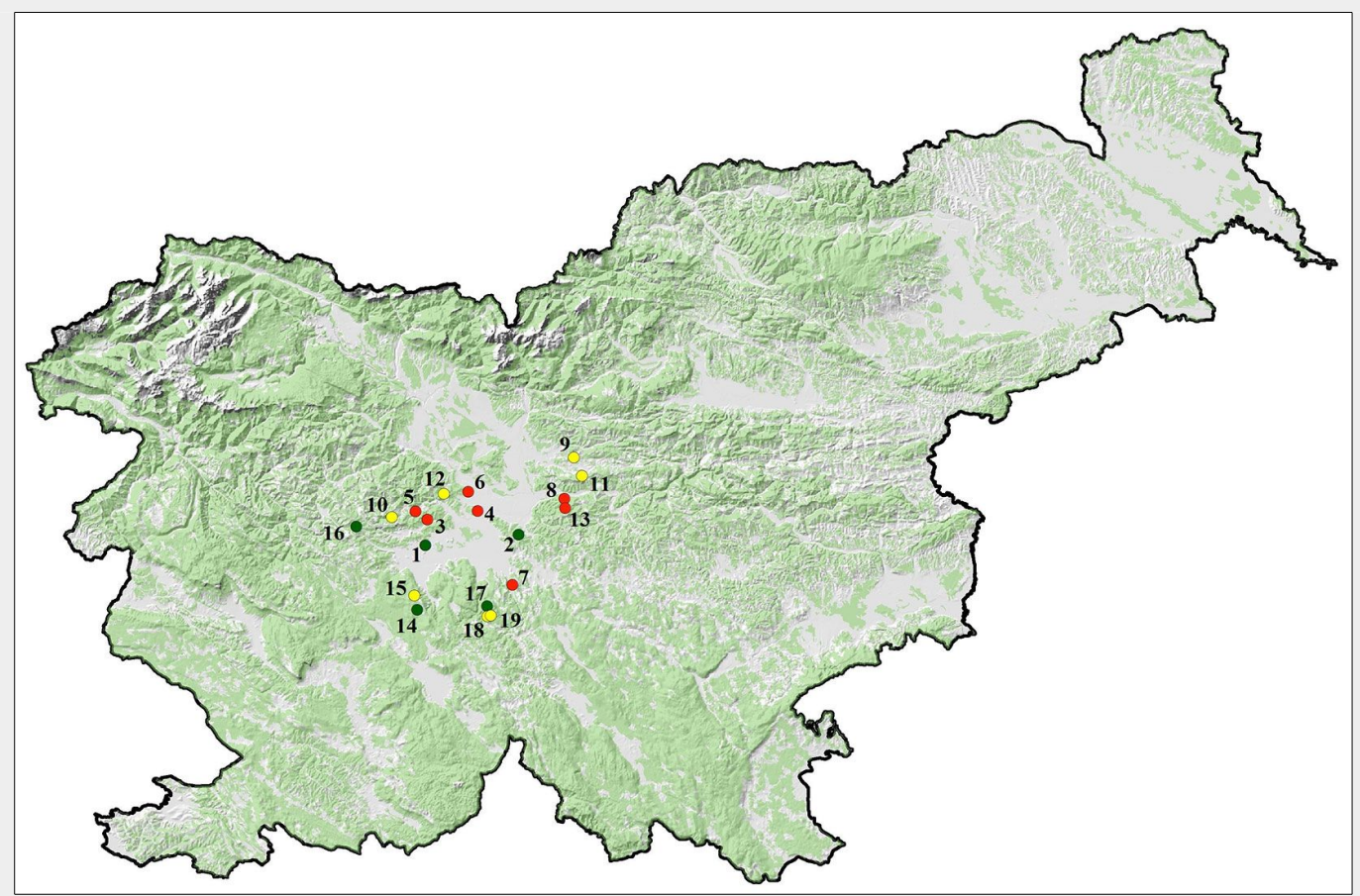

Fig. 1 - Trap locations in stands of common beech (yellow), sessile oak (red) and silver fir (green). The numbers on the map match the stand numbers in Tab. 1. 
same amount of fresh pure ethanol was added to the ethanol-containing bottle. The mean release rate of ethanol during the sampling period was $1.65 \mathrm{ml} \mathrm{day}^{-1}$.

Samples were analyzed using an Olympus SZX12 ${ }^{\circledast}$ stereo microscope, and ambrosia beetles were identified according to the insect identification keys presented by Grüne (1979), Pfeffer (1995) and Faccoli (2008).

\section{Statistical analyses}

For each species, analyses were performed on the total cumulative number of beetles captured during the trapping period per trap. Data were analyzed using the statistical package SPSS ${ }^{\circledR}$ ver. 25 (IBM, Armonk, NY, USA). The Kolmogorov-Smirnov test was performed to check the normality of the data. For non-normally distributed data, $\log (x+1)$ transformations were used to normalize them. A one-way ANOVA was used to test the differences in ambrosia beetle species abundance (only six of the most common species were included in the analysis) and to separately test the differences in the abundance of species between different forest types and between different altitudinal groups. To detect differences in abundance between pairs of samples, Games-Howell post-hoc test was used. The correlation between sanitary felling and the abundance of $X$. germanus was tested by the Pearson's correlation coefficient. Data on the quantity of sanitary logging due to the ice storm in 2014 at individual trap locations were obtained from the Slovenia Forest Service database (ZGS 2017).

\section{Results}

\section{Distribution and abundance of $X$.} germanus and other ambrosia bark beetles

We trapped eleven species of ambrosia beetles: three non-native and eight native to Europe (Tab. 2). There were significant differences in beetle abundance between the different species (one-way ANOVA: $\left.F_{[5,108]}=34.026, p<0.001\right)$. Non-native $X$. germanus represented $71.8 \%$ of the total catch, and the results of the post-hoc test (Tab. 2) show that it was significantly more abundant ( $p<0.05$ - Games-Howell post-hoc test) than the other five most common species: Xyleborinus saxesenii (Ratzeburg, 1837 ) at $20.0 \%$, Xyleborus monographus (Fabricius, 1792 ) at 3.6\%, Anisandrus dispar (Fabricius, 1792 ) at $2.5 \%$, Trypodendron domesticum (Linnaeus, 1758 ) at $1.2 \%$ and Trypodendron signatum (Fabricius, 1787) at $0.6 \%$. $X$. germanus was the most abundant species at 18 of the 19 locations (at one location, it was outcompeted by $X$. saxesenii). The other two non-native species were rare. Twelve specimens of Gnathotrichus materiarius (Fitch, 1858) and one specimen of Xyleborinus attenuatus (Blandford, 1894) were caught. Four species, namely, $X$. germanus, $X$. saxesenii, $A$. dispar and T. signatum, were caught at all 19 sampled loca-

Tab. 1 - Data on trap locations.

\begin{tabular}{|c|c|c|c|c|c|c|}
\hline $\begin{array}{l}\text { Stand } \\
\text { no. }\end{array}$ & Local unit & Latitude & Longitude & $\begin{array}{l}\text { Dominant tree } \\
\text { species }\end{array}$ & $\begin{array}{l}\text { Altitude } \\
\text { (m a.s.I.) }\end{array}$ & $\begin{array}{l}\text { Altitude } \\
\text { group }\end{array}$ \\
\hline 1 & Vrhnika & $45^{\circ} 59^{\prime} 52^{\prime \prime}$ & $14^{\circ} 21^{\prime} 42^{\prime \prime}$ & Abies alba & 303 & 1 \\
\hline 2 & Domžale & $46^{\circ} 01^{\prime} 03^{\prime \prime}$ & $14^{\circ} 35^{\prime} 24^{\prime \prime}$ & Abies alba & 328 & I \\
\hline 3 & Vrhnika & $46^{\circ} 00^{\prime} 20^{\prime \prime}$ & $14^{\circ} 20^{\prime} 11^{\prime \prime}$ & Quercus petraea & 329 & I \\
\hline 4 & Ljubljana & $46^{\circ} 03^{\prime} 27^{\prime \prime}$ & $14^{\circ} 29^{\prime} 20^{\prime \prime}$ & Quercus petraea & 335 & I \\
\hline 5 & Ljubljana & $46^{\circ} 02^{\prime} 32^{\prime \prime}$ & $14^{\circ} 21^{\prime} 58^{\prime \prime}$ & Quercus petraea & 344 & I \\
\hline 6 & Ljubljana & $46^{\circ} 05^{\prime} 26^{\prime \prime}$ & $14^{\circ} 27^{\prime} 57^{\prime \prime}$ & Quercus petraea & 357 & I \\
\hline 7 & Škofljica & $45^{\circ} 55^{\prime} 53^{\prime \prime}$ & $14^{\circ} 34^{\prime} 32^{\prime \prime}$ & Quercus petraea & 413 & I \\
\hline 8 & Domžale & $46^{\circ} 04^{\prime} 45^{\prime \prime}$ & $14^{\circ} 42^{\prime} 07^{\prime \prime}$ & Quercus petraea & 452 & II \\
\hline 9 & Domžale & $46^{\circ} 08^{\prime} 59^{\prime \prime}$ & $14^{\circ} 43^{\prime} 31^{\prime \prime}$ & Fagus sylvatica & 499 & II \\
\hline 10 & Ljubljana & $46^{\circ} 02^{\prime} 45^{\prime \prime}$ & $14^{\circ} 16^{\prime} 42^{\prime \prime}$ & Fagus sylvatica & 502 & II \\
\hline 11 & Domžale & $46^{\circ} 07^{\prime} 07^{\prime \prime}$ & $14^{\circ} 44^{\prime} 41^{\prime \prime}$ & Fagus sylvatica & 529 & II \\
\hline 12 & Ljubljana & $46^{\circ} 05^{\prime} 12^{\prime \prime}$ & $14^{\circ} 24^{\prime} 20^{\prime \prime}$ & Fagus sylvatica & 574 & II \\
\hline 13 & Domžale & $46^{\circ} 03^{\prime} 48^{\prime \prime}$ & $14^{\circ} 42^{\prime} 14^{\prime \prime}$ & Quercus petraea & 589 & II \\
\hline 14 & Vrhnika & $45^{\circ} 53^{\prime} 14^{\prime \prime}$ & $14^{\circ} 20^{\prime} 35^{\prime \prime}$ & Abies alba & 713 & III \\
\hline 15 & Vrhnika & $45^{\circ} 54^{\prime} 42^{\prime \prime}$ & $14^{\circ} 20^{\prime} 06^{\prime \prime}$ & Fagus sylvatica & 749 & III \\
\hline 16 & Ljubljana & $46^{\circ} 01^{\prime} 45^{\prime \prime}$ & $14^{\circ} 11^{\prime} 29^{\prime \prime}$ & Abies alba & 801 & III \\
\hline 17 & Škofljica & $45^{\circ} 53^{\prime} 41^{\prime \prime}$ & $14^{\circ} 30^{\prime} 49^{\prime \prime}$ & Abies alba & 860 & III \\
\hline 18 & Škofljica & $45^{\circ} 52^{\prime} 39^{\prime \prime}$ & $14^{\circ} 30^{\prime} 53^{\prime \prime}$ & Fagus sylvatica & 900 & III \\
\hline 19 & Škofljica & $45^{\circ} 52^{\prime} 43^{\prime \prime}$ & $14^{\circ} 31^{\prime} 24^{\prime \prime}$ & Fagus sylvatica & 941 & III \\
\hline
\end{tabular}

tions.

$X$. germanus was most abundant in beech-dominated stands (Fig. 2) and at medium altitudes (Fig. 3). Although the mean catch in beech stands was almost three times larger than that in oak stands and more than seven times larger than that in fir stands, the differences were not significant (one-way ANOVA: $F_{[2,16]}=3.346$, $\mathrm{p}=0.061$ ). Similarly, the mean catch at medium altitudes was more than three times larger than that at lower altitudes and more than four times larger than that at higher altitudes, but again, the differences were not significant (one-way ANOVA: $\left.F_{[2,16]}=1.829, p=0.193\right)$. However, it should be pointed out that $47.3 \%$ of $X$. germanus specimens were caught at one beech stand

Tab. 2 - Species of ambrosia beetles caught in ethanol-baited traps. The total and mean number \pm standard error (SE) of individuals and number of sites (out of 19) where each species was trapped are shown. Means followed by the same letter were not significantly different ( $p>0.05)$ after Games-Howell post-hoc test. (*): Non-native species.

\begin{tabular}{|lccc|}
\hline Species & $\begin{array}{c}\text { No. of } \\
\text { sites }\end{array}$ & $\begin{array}{c}\text { Total no. of } \\
\text { individuals }\end{array}$ & Mean \pm SE \\
\hline Xylosandrus germanus * & 19 & 67592 & $3557.5 \pm 1611.5^{\mathrm{a}}$ \\
\hline Xyleborinus saxesenii & 19 & 18825 & $990.8 \pm 220.7^{\mathrm{b}}$ \\
\hline Xyleborus monographus & 14 & 3385 & $178.2 \pm 138.1^{\mathrm{c}}$ \\
\hline Anisandrus dispar & 19 & 2336 & $122.9 \pm 20.5^{\mathrm{d}}$ \\
\hline Trypodendron domesticum & 17 & 1127 & $59.3 \pm 15.9^{\mathrm{c}, \mathrm{d}}$ \\
\hline Trypodendron signatum & 19 & 558 & $29.4 \pm 5.3^{\mathrm{d}}$ \\
\hline Xyleborus dryographus & 11 & 208 & $10.9 \pm 4.5$ \\
\hline Trypodendron lineatum & 6 & 59 & $3.1 \pm 1.5$ \\
\hline Gnathotrichus materiarius * & 4 & 12 & $0.6 \pm 0.4$ \\
\hline Xyleborus cryptographus & 1 & 1 & $0.1 \pm 0.1$ \\
\hline Xyleborinus attenuatus * & 1 & 1 & $0.1 \pm 0.1$ \\
\hline Total & 19 & 94104 & $4952.8 \pm 1802.9$ \\
\hline
\end{tabular}

at a medium altitude. If we eliminate this between altitudes were even more non-significant ( $p=0.506$ - Games-Howell post-hoc test), while the differences between different forest types remained at a similar level $(p=0.063)$. Although the differences were not significant (oak-fir: $p=0.122$; beech-fir: $\mathrm{p}=0.063$ - Games-Howell post-hoc test), fir stands proved to be the least suitable for $X$. germanus. The abundance of the species in oak and beech stands was quite similar ( $p=0.568$ - Games-Howell post-hoc test), especially if we removed the extreme beech location from the data $(p=0.909-$ Games-Howell post-hoc test).

Significant differences in the abundance of $X$. saxesenii between different forest location from the analysis, the differences 


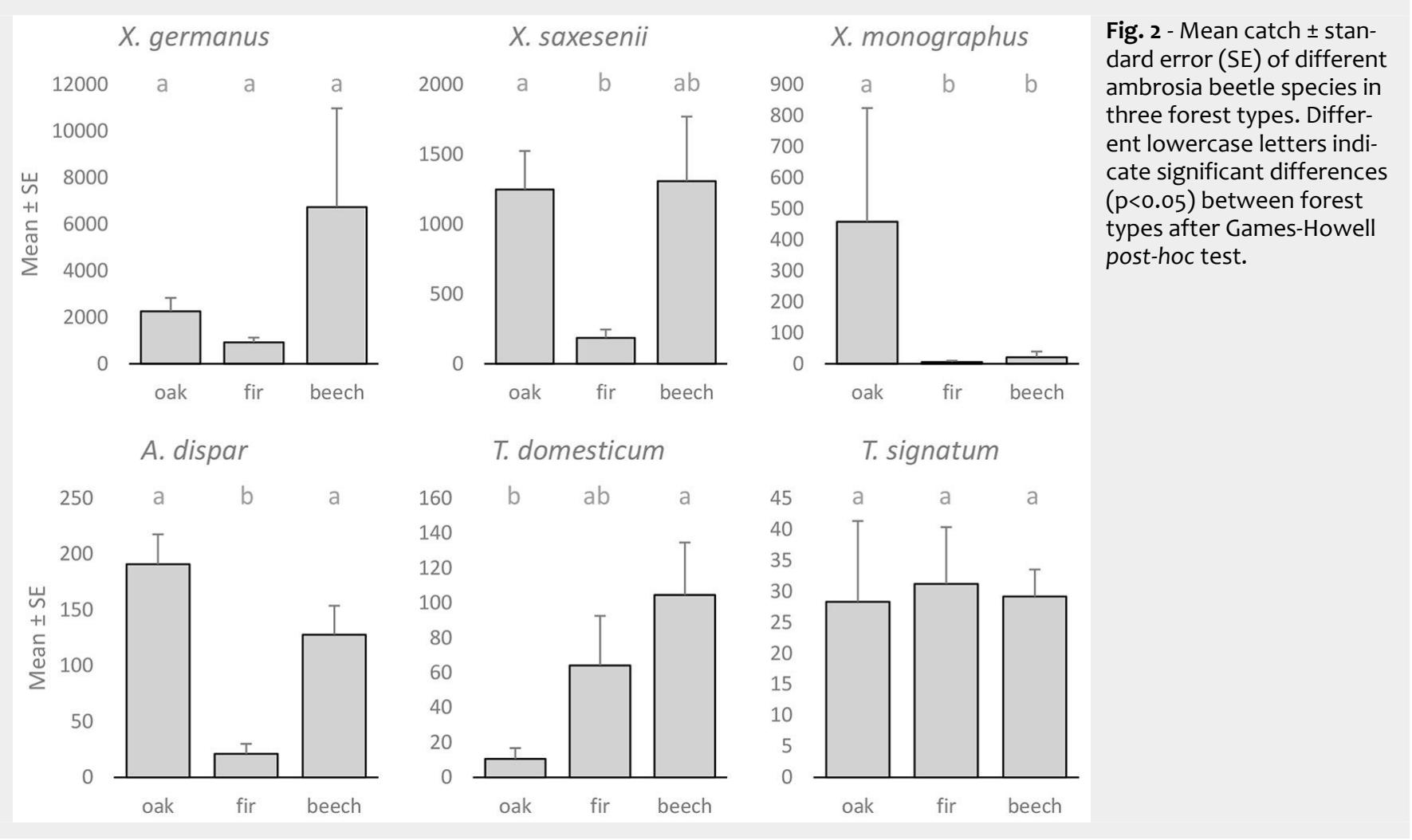

types (one-way ANOVA: $F_{[2,16]}=4.235$, test) were also observed.

ANOVA: $\left.F_{[2,16]}=5.911, p=0.012\right)$. Furthermore, $\mathrm{p}=0.033$ ) and different altitudes (one-way ANOVA: $F_{[2,16]}=7.839, p=0.004$ ) were found. The species was least common in fir stands (Fig. 2) and at higher altitudes (Fig. 3). Significant differences in abundance between fir and oak stands ( $p=0.009$ - Games-Howell post-hoc test) and lower and higher altitudes $(p=0.019$ - Games-Howell post-hoc

$X$. monographus was almost exclusively significant differences between different trapped in oak-dominated stands (Fig. 2) altitudes (one-way ANOVA: $F_{[2,16]}=11.581$, and at lower altitudes (Fig. 3). Nearly 95\% $p=0.001$ ) were also observed.

of all $X$. monographus specimens were The abundance of A. dispar in fir-domitrapped in oak-dominated stands; how- nated stands was significantly lower than ever, $78.0 \%$ were trapped at only one loca- that in oak- ( $p=0.009$ - Games-Howell posttion. Differences in abundance between hoc test) and beech-dominated stands forest types were significant (one-way $(p=0.019$ - Games-Howell post-hoc test)

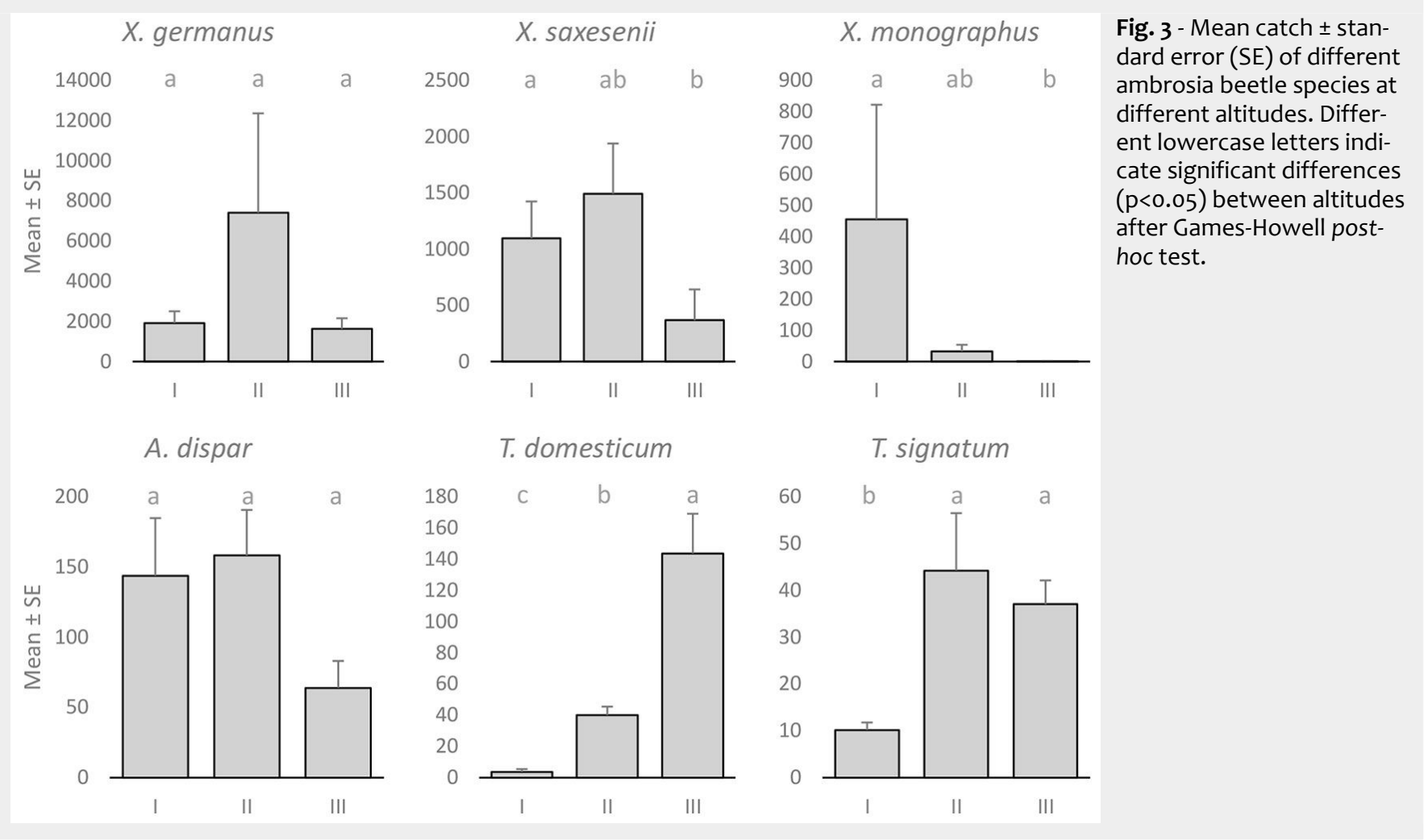


Fig. 4 - Relative share of the catch (number of caught specimens in particular period and particular altitude group / number of caught specimens in entire monitoring period at particular altitude group) of $X$. germanus in different periods and at different altitudes.

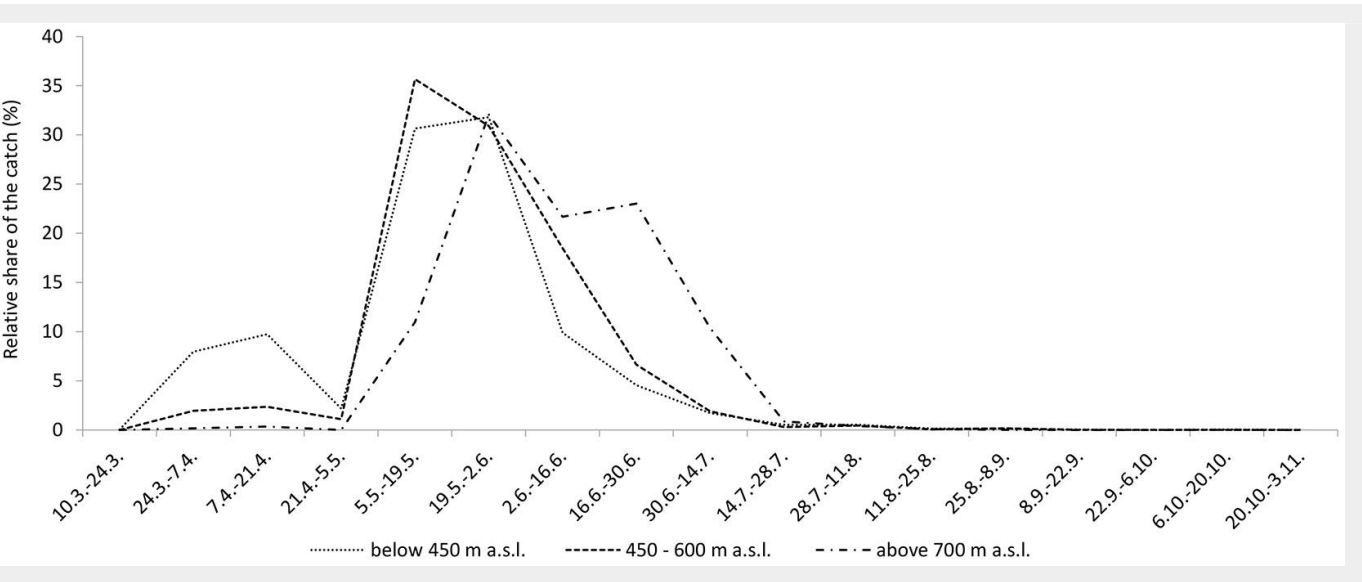

(Fig. 2). The species was less abundant at higher altitudes (Fig. 3), but the differences between different altitudes were not significant (one-way ANOVA: $F_{[2,16]}=1.421$, $\mathrm{p}=0.270)$.

Both Trypodendron species, T. domesticum and T. signatum, were more abundant at higher altitudes (Fig. 3). The catch of $T$. domesticum at higher altitudes was significantly larger than that at medium ( $p=0.002$ - Games-Howell post-hoc test) and lower altitudes ( $p<0.001$ - Games-Howell post-hoc test), and the difference was also significant between medium and lower altitudes ( $p=0.001$ - Games-Howell post-hoc test). The abundance of T. signatum at lower altitudes was significantly lower than that at medium $(p=0.007-$ Games-Howell post-hoc test) and higher altitudes ( $p<0.001$ - Games-Howell post-hoc test), but there was no significant difference ( $p=0.989$ - Games-Howell post-hoc test) between medium and higher altitudes. The catch of $T$. signatum was evenly distributed between different forest types (Fig. 2), while a significant difference (oneway ANOVA: $F_{[2,16]}=6.794, p=0.007$ ) in the abundance of $T$. domesticum between different forest types was found. There was a significant difference between beech- and oak-dominated stands ( $p=0.002$ - GamesHowell post-hoc test).

\section{Flight period of $X$. germanus}

The first $X$. germanus specimens were trapped in the first monitoring period (Fig. 4), between 10 and 24 March, but only in three stands at lower altitudes. In the second monitoring period, the species was trapped at 12 additional locations. At the locations above $800 \mathrm{~m}$ a.s.l., $X$. germanus appeared in the third monitoring period ( 2 locations) or, even later, in the fifth monitoring period (2 locations).

The flight period at the end of April was interrupted due to cold and wet weather (Fig. 4). At lower and medium altitudes, peak flight activity appeared between 5 May and 2 June. At higher altitudes (above $700 \mathrm{~m}$ a.s.l.), peak flight activity appeared between 19 May and 2 June, but the catch was relatively large until the end of June. By the end of July, more than $99.0 \%$ of all
$X$. germanus specimens had been trapped. A second peak in flight activity, which would indicate the development of the second generation, was not observed. However, $X$. germanus specimens were still sporadically caught in September and October.

\section{Ice storm impact on the abundance of $X$. germanus}

A catastrophic ice storm damaged Slovenian forests in February 2014. The positive correlation between the amount of sanitary felling in the period from 2014 to 2017 and the abundance of Xylosandrus germanus was not significant (one-tailed Pearson's correlation coefficient: $r=0.308$, $\mathrm{p}=0.10$ ). However, if we excluded the year 2014 and considered only the period from 2015 to 2017, the positive correlation was higher and significant (one-tailed Pearson's correlation coefficient: $r=0.41, p=0.04$ ). Furthermore, the catch of $X$. germanus at one beech stand was extremely large. If we remove this data, the positive correlation was even higher and more significant (onetailed Pearson's coefficient: $r=0.481$, $\mathrm{p}=0.022$ ).

\section{Discussion}

Less than 10 years after its first discovery, $X$. germanus is already the most abundant ambrosia beetle species in the research area. The species was trapped at all 19 sampled locations. It was the most common species at all locations except one and represented $71.8 \%$ of all ambrosia beetles caught in this study. Similar dominance has also been reported for other parts of Europe. In Belgium, X. germanus constituted $79.6 \%$ and $84.0 \%$ of all trapped scolytids in two monitoring studies in beech forest stands near Brussels (Grégoire et al. 2001). In a large monitoring project of saproxylic beetles near Vienna in Austria, $X$. germanus represented $70 \%$ of all identified individuals (Holzinger et al. 2014). Most recently, in a study located in northeastern Italy, $X$. germanus was the most commonly trapped ambrosia bark beetle (58.7\% - Rassati et al. 2016a). Our results refer only to ambrosia bark beetles (Tab. 2); however, if we include the data on other beetles, individuals of $X$. germanus represented $71.6 \%$ of all bark beetles and $65.4 \%$ of all beetles. In addition to Curculionidae, Salpingidae was the most commonly trapped beetle family in our study.

Klimetzek et al. (1986) tested different ethanol release rates and found a positive correlation between the ambrosia beetle catch and ethanol release rates. However, some authors have reported that high ethanol release rates may have an inhibitory effect and reduce the catch of ambrosia beetles (Salom \& McLean 1990, Ranger et al. 2011, Galko et al. 2014). The release rate in our study was relatively high and could have had a negative impact on some species. However, based on unpublished data from experiments in which we used nonbaited traps, we believe that a lower ethanol release rate would not have affected the proportion of $X$. germanus in the catches.

As in some other studies in Europe (Markalas \& Kalapanida 1997, Galko et al. 2014, Rassati et al. 2016a), X. saxesenii was the most common native ambrosia beetle. It was especially abundant at lower and medium altitudes, but the proportion of this species in the catch was significantly reduced at higher altitudes (Fig. 3). In contrast, the catch of $T$. domesticum at higher altitudes was significantly larger than that at medium and lower altitudes, and therefore, at the three higher locations, T. domesticum was the most common native species. However, when interpreting the results for $T$. domesticum, it is necessary to stress that we missed the beginning and the peak of flight activity at lower and medium altitudes. In the local literature (Titovšek 1988, Jurc 2005), there is information that the species begins to fly in the second half of March, when ambient temperatures reach $13-14{ }^{\circ} \mathrm{C}$, but our study (especially trap catches before 10 March 2017 - data not included in analysis) showed that in the lowlands, T. domesticum already had a peak occurrence before 10 March. According to temperature data from nearby meteorological stations (ARSO 2018), it is assumed that the temperature swarming threshold for $T$. domesticum is lower than that mentioned before, and it could be sim- 
ilar to that in Croatia, where it was found that flight activity starts when daily temperatures rise above $9{ }^{\circ} \mathrm{C}$ (Franjević 2013). However, the abundance of T. domesticum and, to a lesser extent, T. signatum in our lowland forests is certainly greater than our results showed.

In North America X. germanus did not exhibit flight activity until one or two days with a maximum daily temperature of at least $20{ }^{\circ} \mathrm{C}$ (Reding et al. 2013). According to data from the official meteorological station in Ljubljana (ARSO 2018), similar maximum daily temperatures were also measured in the second half of the first monitoring period (between 10 and 24 March). This turned out to be sufficient to induce flight activity in the first $X$. germanus specimens in nearby oak stands with a southern exposition. In the middle of the second monitoring period (between 24 March and 6 April), maximum daily temperatures also exceeded $20^{\circ} \mathrm{C}$ at higher altitudes, and the first $X$. germanus specimens were also trapped at all other traps located below $800 \mathrm{~m}$ a.s.I. On this basis, we assume that the temperature threshold of $20{ }^{\circ} \mathrm{C}$ is also valid in our climatic conditions.

The flight activity of beetles varies from season to season due to different weather conditions in every year. However, Graf \& Manser (2000) reported that the flight activity of $X$. germanus in Switzerland started at the beginning of May, with a maximum in June and July. Similar observations were also made in Romania (Olenici et al. 2014). Earlier flight activity of the species was observed in Croatia (Franjević et al. 2016), where swarming began in the beginning of April, with peak flight activity already occurring at the end of April. On the basis of our results, it could be argued that the swarming of the species in lowland forests may take place by the middle or end of March. Maximum flight activity in our study was observed in May and early June in forests below $600 \mathrm{~m}$ a.s.l. and at the end of May and in June in forests above $700 \mathrm{~m}$ a.s.l. However, we assume that the cold and wet weather at the end of April prevented an even earlier occurrence of peak flight activity and that the peak occurrence of $X$. germanus could occur as soon as the end of April, as formerly recorded in Croatia.

In Central Europe $X$. germanus has one generation per year (Bruge 1995, Henin \& Versteirt 2004), while in Italy two generations per year have been observed (Rassati et al. 2016b). The first peak of occurrence in Italy is in the middle of May and the second at end of July or at the beginning of August (M. Faccoli, personal communication). Because we observed the first peak in May, we also expected the occurrence of a second peak in July or August, but it obviously did not appear (Fig. 4). Therefore, we assume that only one generation per year develops in central Slovenia.

Minimum winter temperatures are pre- sumably the key limiting factor for the survival of X. germanus (Bruge 1995, Henin \& Versteirt 2004, Galko et al. 2019). According to Slovenian Environment Agency data (Cegnar 2017), January 2017 was the coldest January in the last three decades. The average monthly temperature in Ljubljana was $-3.1{ }^{\circ} \mathrm{C}$, which is $3.5^{\circ} \mathrm{C}$ lower than the average of the period 1981-2010. The abundance of $X$. germanus in our traps after such exceptional conditions indicates that winter temperatures in the lowlands of Slovenia are most likely not a real limiting factor for the species. However, at higher altitudes, conditions are more extreme, and the vertical spread of the species is certainly limited. In our research, $X$. germanus was found along the entire altitudinal gradient between 303 and $941 \mathrm{~m}$. Our results thus confirm the findings from Slovakia (Galko et al. 2019) and Romania (Olenici et al. 2014), where the species appeared at altitudes of approximately 900 $\mathrm{m}$. However, the catch of $X$. germanus in the trap at the highest altitude (941 m a.s.l.) was relatively large (2060 specimens). We therefore assume that we did not reach the upper boundary of the appearance of the species in Slovenia. In Slovakia, $X$. germanus was found to attack spruce logs at an altitude of $1020 \mathrm{~m}$, but it has not yet been found in forests above $1100 \mathrm{~m}$ a.s.l. (Galko et al. 2019).

In Slovakia, altitude had a significant effect and forest type (oak, beech, spruce) had a nonsignificant effect on the abundance of X. germanus (Galko et al. 2019). However, the results from Slovakia suggest that beech forests between approximately 500 and $700 \mathrm{~m}$ a.s.l. are optimal for the species. Warmer and dryer oak forests at lower altitudes, and cool submontane mountain forests are presumably less suitable for the beetle. Our findings are to some extent also in accordance with the suggested optimal site conditions. The abundance of $X$. germanus in our study was also greatest at medium altitudes (450-600 $\mathrm{m}$ a.s.l.) and in beech stands (Fig. 2, Fig. 3). However, the differences between altitude groups and forest types in our study were not significant. Our results actually show that lower elevation oak forests are equally suitable for $X$. germanus compared to higher elevation beech forests, while fir stands proved to be the least suitable for $X$. germanus. The abundance of $X$. germanus in Italy (Rassati et al. 2016a) was significantly higher in sweet chestnut-dominated forests than in hop-hornbeam- and beech-dominated forests. Therefore, the relatively large admixture of sweet chestnut in the oak stands in our study could have contributed to the large abundance of the species in oak stands. Indeed, ongoing research work in Slovenia also shows the massive presence of $X$. germanus in other forest types, demonstrating that the species is a habitat generalist.

In most cases, $X$. germanus attacks hosts that are stressed, dying or recently dead
(Ranger et al. 2016). Forests damaged by natural disasters are therefore a suitable environment for the development of the species (Jurc et al. 2010). In February 2014, Slovenia was hit by an ice storm that damaged approximately 9.3 million $\mathrm{m}^{3}$ of trees over an area of more than 600,000 ha (ZGS 2014). The forests in our research area were also damaged, but to varying degrees. The measure of damage is the amount of sanitary logging carried out in the period after the ice storm. If we take into account the entire period (2014-2017), the positive correlation between the amount of sanitary felling and the abundance of $X$. germanus is weak to moderate and not significant. However, if we exclude 2014, the positive correlation is higher and significant. Thus, we can conclude that the ice storm had a positive effect on the abundance of the species, especially in areas where sanitary logging was delayed.

In addition to $X$. germanus, two other non-native ambrosia beetle species were trapped in our study. G. materiarius is native to North America and was introduced to Europe in the 1930s (Balachowsky 1949). In Slovenia, it was first found in 2003 during an inventory of fauna at Brdo pri Kranju (Geister 2004). Since then, it has often been found in traps intended for monitoring of Monochamus beetles in pine stands around Slovenia (Jurc et al. 2012). Damage caused by this species has not yet been recorded. To our knowledge, the specimen of $X$. attenuatus caught in our study is the first finding of this species in Slovenia. It was trapped in the period between 14 and 28 July in an oak-dominated forest in the outskirts of Ljubljana. In another monitoring program that took place in 2018, another specimen of $X$. attenuatus was caught in an ethanol-baited trap located near Tolmin in the western part of Slovenia. However, this species was first found in Europe in 1987 (Knízek 1988). Its exact distribution is not clear because of confusion with the closely related $X$. saxesenii; nevertheless, it is estimated to be widely distributed within the EU (Björklund \& Boberg 2017b).

\section{Conclusions}

The spread of $X$. germanus in Europe has accelerated since 2000 (Galko et al. 2019). Based on the results of this study and observations in other parts of Slovenia, we can conclude that the species has become established in Slovenia. Moreover, as in some other countries in Europe (Grégoire et al. 2001, Holzinger et al. 2014, Rassati et al. 2016a, Galko et al. 2019), monitoring programs using ethanol-baited traps show that $X$. germanus has become a dominant ambrosia beetle species regardless of forest type. Findings of the species at higher altitudes (Olenici et al. 2014, Galko et al. 2019, and this study) indicate the vertical spread of the species in Europe, which is most likely the result of climate change.

Despite the widespread and massive 
presence of the species in our forests, damage to standing trees, with rare exceptions for individual trees, has not yet been recorded. In fact, it is very difficult to find signs of the presence of the species in the forest, although we know that the $X$. germanus population is large. Therefore, despite the damage recorded in 2016 when $X$. germanus infested a larger amount of timber that was not removed from the forest immediately after logging (Hauptman et al. 2018), we agree with Lakatos \& Kajimura (2007) who stated that $X$. germanus in Europe is a secondary pest that does not cause remarkable damage. However, there are some examples of beetle-fungus symbioses that have shifted from being a secondary pest on a wide range of hosts to becoming a primary pest on a narrow range of hosts in their introduced ranges (Hulcr \& Dunn 2011). In some regions of North America, a similar shift may have already occurred for $X$. germanus (Björklund \& Boberg 2017a); therefore, there is a risk that the species will become an important pest in European orchards, plantations, nurseries and vineyards, as is currently the case in North America (Galko et al. 2019). Furthermore, with climate change, we can expect more stressful events and large-scale disruptions in forests and, consequently, more attacks of $X$. germanus on weakened or fallen trees.

Maintaining tree health is essential to prevent $X$. germanus attacks (Ranger et al. 2016). This is, for example, easier to achieve in forest nurseries than in forest stands. The most important measure to prevent attacks and economic damage in forests is to transport felled logs from the forests immediately after harvesting and to store the wood in places that allow for proper drying (Graf \& Manser 2000). Another option is to carry out logging, transport and storage of lumber outside of the main flight period of the species (Franjević et al. 2016).

\section{Acknowledgements}

This research was financed by the Pahernik Foundation and the Slovenian Research Agency through research program $\mathrm{P}_{4}$ 0059. We are grateful to Daniel Borkovič (Department of Forestry and Renewable Forest Resources, Biotechnical Faculty, University of Ljubljana, Slovenia) for his participation in the fieldwork.

\section{References}

ARSO (2018). Meteorological data of the Environmental Agency of the Republic of Slovenia. Lubiana, Slovenia, web site. [online] URL: https://meteo.arso.gov.si

Balachowsky A (1949). Coléopteres Scolytides [Bark beetles]. Faune de France 50: 1-320. [in French]

Björklund N, Boberg J (2017a). Rapid pest risk analysis Xylosandrus germanus. Swedish University of Agricultural Sciences, Uppsala, Sweden, pp. 22.

Björklund N, Boberg J (2017b). Rapid pest risk analysis Xyleborinus attenuatus. Swedish University of Agricultural Sciences, Uppsala, Sweden, pp. 17.

Bouget C, Noblecourt T (2005). Short-term development of ambrosia and bark beetle assemblages following a windstorm in French broadleaved temperate forests. Journal of Applied Entomology 129 (6): 300-310. - doi: 10.1111/j.143 9-0418.2005.00970.x

Bruge H (1995). Xylosandrus germanus (Blandford, 1894) (Belg. sp. nov.) (Coleoptera Scolytidae). Bulletin et Annales de la Société Royale Belge d'Entomologie 131: 249-264. [online] URL: http://www.cabdirect.org/cabdirect/abstr act/19961103560

Cegnar T (2017). Podnebne razmere $v$ januarju 2017 [Climate in January 2017]. Naše okolje. Mesečni bilten Agencije RS za okolje 24 (1): 3-24. [in Slovenian]

EPPO (2018). Xylosandrus germanus. EPPO Global Database, European and Mediterranean Plant Protection Organization, Paris, France, web site. [online] URL: http://gd.eppo.int/tax on/XYLBGE/distribution

Faccoli M (2008). First record of Xyleborus atratus Eichhoff from Europe, with an illustrated key to the European Xyleborini (Coleoptera: Curculionidae: Scolytinae). Zootaxa 1772: 55-62. doi: 10.11646/zootaxa.1772.1.2

Franjević M (2013). Bivoltinism of European hardwood ambrosia beetle Trypodendron domesticum in Croatian lowland oak stands of Jastrebarski Lugovi. Šumarski list 137 (9-10): 495-498.

Franjević M, Poršinsky T, Duka A (2016). Integrated oak timber protection from ambrosia bark beetles: economic and ecological importance in harvesting operations. Croatian Journal of Forest Engineering 2016 (37): 353-364. [online] URL: http://hrcak.srce.hr/173835

Galko J, Nikolov C, Kimoto T, Kunca A, Gubka A, Vakula J, Zúbrik M, Ostrihon M (2014). Attraction of ambrosia beetles to ethanol baited traps in a Slovakian oak forest. Biologia 69: 1376-1383. - doi: 10.2478/s11756-014-0443-z

Galko J, Dzurenko M, Ranger CM, Kulfan J, Kula E, Nikolov C, Zubrik M, Zach P (2019). Distribution, habitat preference, and management of the invasive ambrosia beetle Xylosandrus germanus (Coleoptera: Curculionidae, Scolytinae) in European forests with an emphasis on the West Carpathians. Forests 10 (1): 10. - doi: 10.3390/f10010010

Geister I (2004). Popis rastlin in živali na Brdu pri Kranju [An inventory of plants and animals of Brdo near Kranj]. Kronika (Ljubljana) 52 (2): 273-284. [in Slovenian]

Graf E, Manser P (2000). The imported Japanese scolytid beetle Xylosandrus germanus: biology and damage potential for stored round timber compared to Xyloterus lineatus and Hylecoetus dermestoides. Schweizerische Zeitschrift fur Forstwesen 151 (8): 271-281. - doi: 10.3188/szf.2 000.0271

Groschke F (1953). Der "schwarze Nutzholzborkenkäfer", Xylosandrus germanus Blandf., ein neuer Schädling in Deutschland [The "black ambrosia" Xylosandrus germanus Blandf., a new pest in Germany]. Zeitschrift für Angewandte Entomologie 34: 297-302. [in German] doi: $10.1007 / B F 02007076$

Grégoire JC, Piel F, De Proft M, Gilbert M (2001).
Spatial distribution of ambrosia-beetle catches: a possibly useful knowledge to improve masstrapping. Integrated Pest Management $\mathrm{Re}$ views 6 (3-4): 237-242. - doi: 10.1023/A:102572 3402355

Grüne S (1979). Handbuch zur Bestimmung der Europäischen Borkenkäfer [Brief illustrated key to european bark beetles]. Verlag M \& H Schaper, Hannover, Germany, pp. 184. [in German]

Hauptman T, Pavlin R, Jurc M (2018). Ambrozijski podlubnik (Xylosandrus germanus) [Ambrosia bark beetle (Xylosandrus germanus)]. Gozdarski vestnik 5/6 (76): 3-4. [in Slovenian]

Henin JM, Versteirt V (2004). Abundance and distribution of Xylosandrus germanus (Blandford 1894) (Coleoptera, Scolytidae) in Belgium: new observations and an attempt to outline its range. Journal of Pest Science 77: 57-63. - doi: 10.1007/s10340-003-0030-5

Holzinger WE, Frie T, Holzer E, Mehlmauer P (2014). Xylobionte Käfer (Insecta: Coleoptera part.) in Wäldern des Biosphärenparks Wienerwald (Österreich: Niederösterreich, Wien) [Saproxylic Beetles (Insecta: Coleoptera part.) in forests of the Biosphere Reserve Wienerwald (Austria: Lower Austria, Vienna)]. Wissenschaftliche Mitteilungen des Niederösterreichischen Landesmuseums, St. Pölten 25: 331362. [in German]

Hulcr J, Dunn RR (2011). The sudden emergence of pathogenicity in insect-fungus symbioses threatens naive forest ecosystems. Proceedings of the Royal Society of London B: Biological Sciences 278 (1720): 2866-2873. - doi: 10.1098/rspb.2011.1130

Hulcr J, Atkinson T, Cognato A, Jordal B, MCKenna D (2015). Morphology, taxonomy and phylogenetics of bark beetles. In: "Bark Beetles: Biology and Ecology of Native and Invasive Species" (Vega FE, Hofstetter RW eds). Academic Press, San Diego, CA, USA, pp. 41-84. doi: 10.1016/B978-0-12-417156-5.00002-2

Jurc M (2005). Gozdna zoologija (univerzitetni učbenik) [Forest Zoology (University textbook)]. Bitehniška fakulteta, Oddelek za Gozdarstvo in obnovljive gozdne vire, Ljubljana, Slovenia, pp. 348. [in Slovenian]

Jurc M, Zavrtanik Z, Reščič M (2010). Tujerodni podlubnik Xylosandrus germanus se širi $v$ gozdovih Slovenije [The non-native bark beetle $X y$ losandrus germanus is spreading in the forests of Slovenia]. Novice iz varstva gozdov 3: 10-13. [in Slovenian] [online] URL: http://www.zdravg ozd.si/nvg/prispevek.aspx?idzapis=3-8

Jurc M, Borkovič D, Pavlin R, Meterc G (2011). Xylosandrus germanus (Blandfort, 1894) (Curculionidae: Scolytinae) in Slovenia. In: Proceeding of the "SIEEC 22, Symposium Internationale Entomofaunisticum Europae Centralis". Varaždin (Croatia), 26 June - 03 July 2011. Gradski muzej, Varaždin, Croatia, pp. 33-34.

Jurc M, Bojovic S, Fernaández MF, Jurc D (2012). The attraction of cerambycids and other $x y$ lophagous beetles, potential vectors of Bursaphelenchus xylophilus, to semiochemicals in Slovenia. Phytoparasitica 40: 337-349. - doi: 10.1007/s12600-012-0234-4

Kirkendall LR, Faccoli M (2010). Bark beetles and pinhole borers (Curculionidae, Scolytinae, Platypodinae) alien to Europe. ZooKeys 56: 227251. - doi: 10.3897/zookeys.56.529 
Kirkendall LR (1983). The evolution of mating systems in bark and ambrosia beetles (Coleoptera: Scolytidae and Platypodidae). Zoological Journal of the Linnean Society 77: 293-352. doi: 10.1111/j.1096-3642.1983.tboo858.x

Klimetzek D, Köhler J, Vité JP, Kohnle U (1986). Dosage response to ethanol mediates host selection by "secondary" bark beetles. Naturwissenschaften 73 (5): 270-271. - doi: 10.1007/BFo 0367783

Knízek M (1988). Xyleborus alni Niijima, 1909. Acta Entomologica Bohemoslovaca 85: 396.

Lakatos F, Kajimura H (2007). Occurrence of the introduced Xylosandrus germanus (Blandford, 1894) in Hungary - A genetic evidence (Coleoptera: Scolytidae). Folia Entomologica Hungarica 68: 97-104. [online] URL: http://www. cabdirect.org/cabdirect/abstract/20083055832

Markalas S, Kalapanida M (1997). Flight pattern of some Scolytidae attracted to flight barrier traps baited with ethanol in an oak forest in Greece. Anzeiger für Schädlingskunde, Pflanzenschutz, Umweltschutz 70 (3): 55-57. - doi: 10.1007/BF01996922

Olenici N, Kníek M, Olenici V, Duduman ML, Biris IA (2014). First report of three scolytid species (Coleoptera: Curculionidae, Scolytinae) in Romania. Annals of Forest Research 57: 89-97. doi: 10.15287/afr.2014.196

Pfeffer A (1995). Zentral- und westpaläarktische Borken- und Kernkäfer (Coleoptera: Scolytidae, Platypodidae) [Central and western Palearctic bark and ambrosia beetles (Coleoptera: Scolyti- dae, Platypodidae)]. Pro Entomologia, Naturhistorisches Museum, Basel, Switzerland, pp. 310. [in German]

Ranger C, Reding M, Gandhi K, Oliver J, Schultz $P$, Cañas L, Herms D (2011). Species dependent influence of (-)-a-pinene on attraction of ambrosia beetles (Coleoptera: Curculionidae: Scolytinae) to ethanol-baited traps in nursery agroecosystems. Journal of Economic Entomology 104 (2): 574-579. - doi: 10.1603/EC10243

Ranger CM, Reding ME, Schultz PB, Oliver JB, Frank SD, Addesso KM, Chong JH, Sampson B, Werle C, Gill S, Krause C (2016). Biology, ecology, and management of nonnative ambrosia beetles (Coleoptera: Curculionidae: Scolytinae) in ornamental plant nurseries. Journal of Integrated Pest Management 7 (1): 25. - doi: 10.1093 /jipm/pmwoo5

Rassati D, Faccoli M, Battisti A, Marini L (2016a). Habitat and climatic preferences drive invasions of non-native ambrosia beetles in deciduous temperate forests. Biological Invasions 18 (10): 2809-2821. - doi: 10.1007/s10530-016-1172-8 Rassati D, Lieutier F, Faccoli M (2016b). Alien wood-boring beetles in Mediterranean regions. In: "Insects and Diseases of Mediterranean Forest Systems" (Payne TD, Lieutier F eds). Springer International Publishing, Cham, Switzerland, pp. 293-327. - doi: 10.1007/978-3-319-2474 4-1_11

Reding ME, Ranger CM, Oliver JB, Schultz PB (2013). Monitoring attack and flight activity of Xylosandrus spp. (Coleoptera: Curculionidae:
Scolytinae): the influence of temperature on activity. Journal of Economic Entomology 106 (4): 1780-1787. - doi: 10.1603/EC13134

Salom SM, McLean JA (1990). Flight and landing behavior of Trypodendron lineatum (Coleoptera: Scolytidae) in response to different semiochemicals. Journal of Chemical Ecology 16 (8): 2589-2604. - doi: 10.1007/BF01017481

Seljak G (2013). Dinamika vnosa tujerodnih fitofagnih žuželk in pršic v Slovenijo [The dynamics of introduction of alien phytophagous insects and mites in Slovenia]. Acta entomologica Slovenica 21 (2): 85-122. [in Slovenian]

Titovšek J (1988). Podlubniki (Scolytidae) Slovenije: obvladovanje podlubnikov [Bark beetles (Scolytidae) of Slovenia: control of bark beetles]. Zveza društev inženirjev in tehnikov gozdarstva in lesarstva Slovenije, Gozdarska založba, Ljubljana, Slovenia, pp. 128. [in Slovenian]

Weber BC, McPherson JE (1983). World list of host plants of Xylosandrus germanus (Blandford) (Coleoptera: Scolytidae). The Coleopterists' Bulletin 37: 114-134. [online] URL: http:// www.jstor.org/stable/4008002

ZGS (2014). The operational plan for the sanitation of the damaged forest after the sleet event in February 2014. Slovenian Forest Service, Ljubljana, Slovenia, pp. 66.

ZGS (2017). Timber: database of tree felling. Slovenian Forest Service, Ljubljana, Slovenia. [CD-ROM] 